\title{
Intra-aortic intimal band presenting as an aortic pseudodissection
}

\author{
Pramod Bonde, MD, MS, FRCS, and David D. Yuh, MD, Baltimore, Md
}

Acute aortic syndromes comprised of aortic dissections, intramural hematomas, and acute penetrating ulcers are associated with a mortality rate of greater than $1 \%$ per hour from the time of clinical presentation and can reach up to $80 \%$ if untreated by the end of 2 weeks. ${ }^{1}$ Diagnostic improvements, including high-resolution computed tomographic angiography (CTA), have significantly reduced false-positive rates and provided expedient diagnoses in patients afflicted with these rapidly evolving and lethal aortic pathologies. ${ }^{2}$ The increased availability of CTA might lead to the detection of aor-

From the Johns Hopkins Cardiac Surgery, Baltimore, Md.

Disclosures: None.

Received for publication Nov 13, 2008; accepted for publication Nov 22, 2008; available ahead of print Feb 23, 2009.

Address for reprints: David D. Yuh, MD, Johns Hopkins Cardiac Surgery, $600 \mathrm{~N}$

Wolfe St/618 Blalock, Baltimore, MD 21287 (E-mail: prambond@hotmail.com).

J Thorac Cardiovasc Surg 2010;139:e64-5

$0022-5223 / \$ 36.00$

Copyright $\odot 2010$ by The American Association for Thoracic Surgery

doi:10.1016/j.jtcvs.2008.11.036 tic pathologies resembling acute aortic dissection. We present a case in which an unusual intimal band without evidence of recent or remote dissection was interpreted on high-resolution CTA as a localized proximal aortic arch dissection.

\section{CLINICAL SUMMARY}

A normotensive 48-year-old woman presented to a community emergency department with back pain radiating to the right subcostal region. She underwent contrast-enhanced thoracic CTA, which revealed what appeared to be an intimal flap consistent with an acute Stanford type A aortic dissection localized to the proximal arch of the aorta. After she was transported on an emergency basis to our facility with this diagnosis, her unusual clinical presentation prompted the acquisition of a gated CTA to rule out an artifactual misinterpretation. On this study, the lesion in question was interpreted as a focal intimal tear of the proximal aortic arch with no appreciable distal or proximal propagation, extravasation, or hematoma (Figure 1). Although the flap was atypical
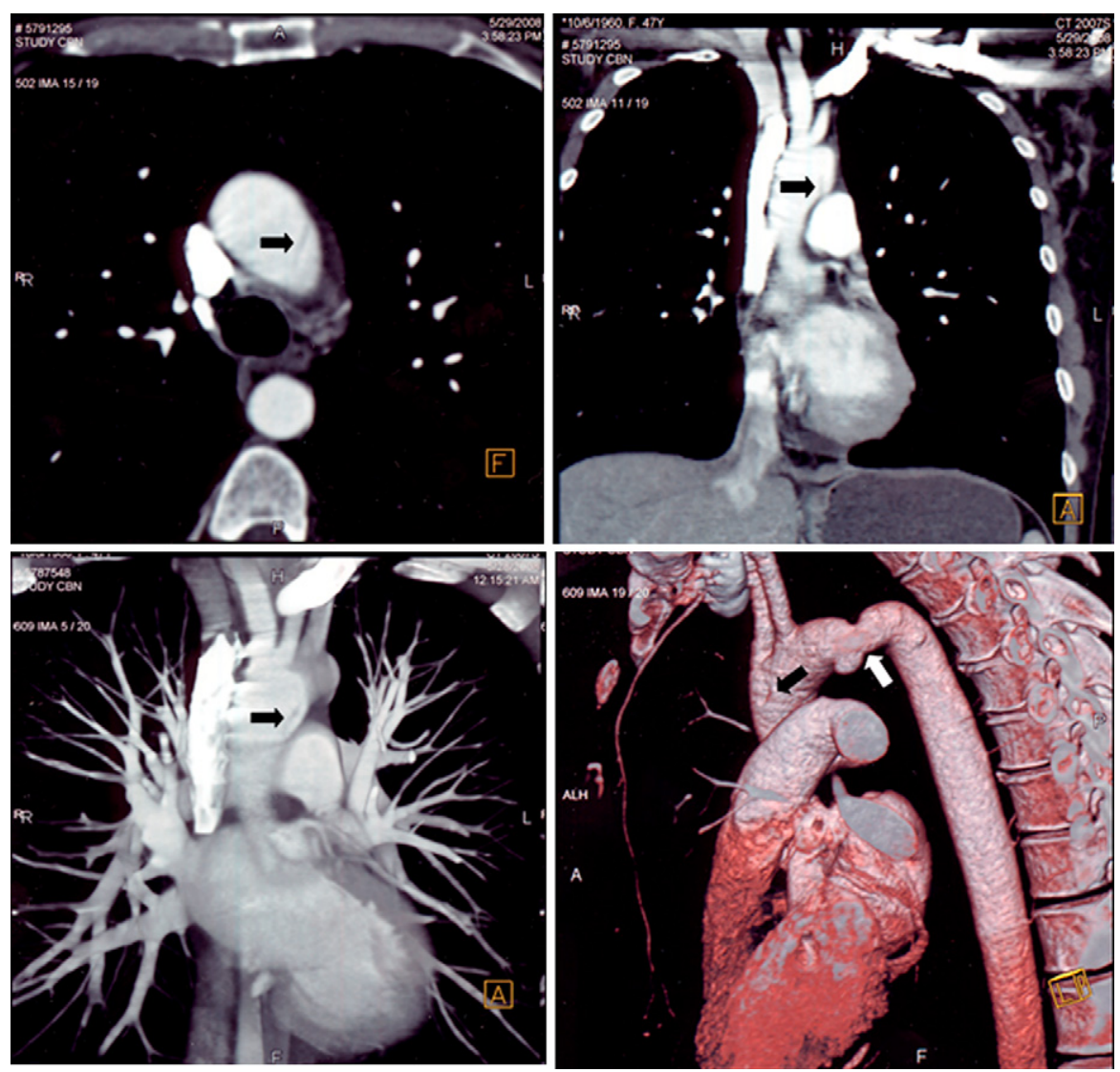

FIGURE 1. Computed tomographic scan imaging with reconstruction to define the "focal intimal tear," as depicted by the black arrow. The white arrow demonstrates pseudocoarctation. 

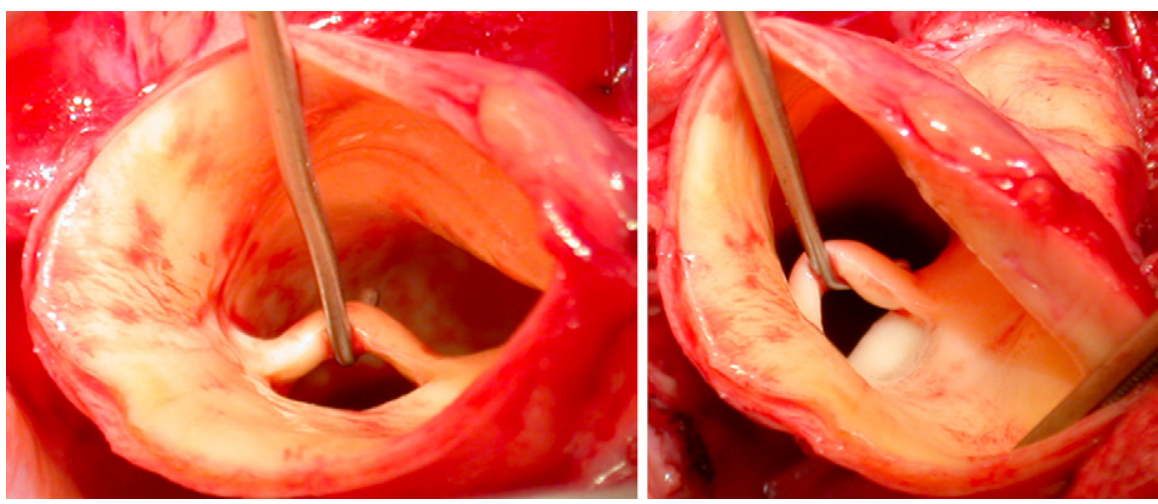

FIGURE 2. Operative findings during circulatory arrest: view from the right side looking down into the aortic arch.

in appearance, it did track medially for several millimeters. Furthermore, the distal aortic arch was slightly ectatic relative to the descending aorta with relative narrowing of the isthmus beyond the lesion, which mimicked a pseudocoarctation. Transesophageal echocardiographic analysis revealed no evidence of a proximal ascending aortic dissection, although the distal ascending aorta and proximal aortic arch could not be visualized.

After careful consideration, we felt compelled to recommend operative exploration and repair of this intimal tear given our concerns that it would evolve into a formal acute dissection. The patient's past medical history was significant for an incidence of carotid vasculitis treated with a short course of steroids. She did not have any stigmata of Marfan's, Ehlers-Danlos, or Loeys-Deitz syndromes.

Transection of the ascending aorta and exploration of the proximal aortic arch under selective antegrade cerebral perfusion revealed a $5-\mathrm{mm} \times 3$-mm intimal bridge on the lesser curve of the proximal aortic arch (Figure 2). It did not appear to be an acute process and did not propagate proximally or distally. The ascending aorta was replaced from the sinotubular junction to the point using a 22-mm Hemashield Platinum Woven Double Velour Vascular graft (Boston Scientific, Natick, Mass). The patient made an uneventful postoperative recovery and was discharged without complication.

Histopathologic examination of the resected ascending aorta revealed focal mild cystic medial degeneration.
The excised intimal band consisted of elastic connective tissue.

\section{DISCUSSION}

Acute aortic syndromes, comprised of aortic dissections, intramural hematomas, and penetrating ulcers, are associated with high mortality rates without expedient surgical treatment. ${ }^{1}$ In this case the small localized appearance of the apparent dissection flap and lack of convincing symptoms prompted us to confirm the diagnosis with a more precise CTA with 3dimensional reconstructions. Despite the radiographic diagnosis of acute dissection, the actual intimal "flap" consisted of an intimal band comprised of elastic connective tissue. This anomaly might be a congenital remnant linked to the unusual appearance of the distal aortic arch. Alternatively, this might be the remnant of a healed localized dissection.

With the widespread use of advanced imaging modalities in emergency departments, it is conceivable that unusual radiographic findings mimicking acute aortic syndromes might pose diagnostic dilemmas. Despite the sophistication of these cutting-edge modalities, this case emphasizes the importance and relevance of clinical correlation when making therapeutic decisions.

\section{References}

1. Anagnostopoulos CE, Prabhakar MJ, Kittle CF. Aortic dissections and dissecting aneurysms. Am J Cardiol. 1972;30:263-273.

2. Chughtai A, Kazerooni EA. CT and MRI of acute thoracic cardiovascular emergencies. Crit Care Clin. 2007;23:835-853. 